\title{
A Miniature 15-50-GHz Medium Power Amplifier
}

\author{
Mei-Chen Chuang, Pei-Si Wu, Ming-Fong Lei, Huei Wang, Yu-Chi Wang*, and Chan Shin Wu* \\ Dept. of Electrical Engineering and Graduate Institute of Communication Engineering, \\ National Taiwan University, Taipei, Taiwan, 106, ROC \\ *WIN Semiconductors Corp., Hwaya Technology Park, Taiwan 333, ROC
}

\begin{abstract}
A miniature power amplifier, which combines two conventional distributed amplifiers and a single transistor amplifier is designed to achieve wide bandwidth, high gain and moderate output power from 15 to $50 \mathrm{GHz}$. This circuit was fabricated using $0.15-\mu \mathrm{m}$ GaAs based pHEMT MMIC technology. The measured small signal gain is $21 \pm 1.5 \mathrm{~dB}$ from 15 to $50 \mathrm{GHz}$, and the output saturated power is $18-22 \mathrm{dBm}$ from 18 to $50 \mathrm{GHz}$ with a miniature size of $1.5 \times 1 \mathrm{~mm} 2$.
\end{abstract}

Index Terms - Broadband, Power amplifier, Monolithic Integrated circuit (MMIC).

\section{INTRODUCTION}

Broad-band power amplifier is very useful since it can cover many bands. Thus, it can be used in many applications without expensing time to fabricate another circuit which designed to cover the other band. Wide-band solid-state power amplifiers are difficult to design, because it is not easy to realize the power and bandwidth at the same time. For frequency higher than $50 \mathrm{GHz}$, the cascaded configuration demonstrated moderate bandwidth [1]-[2]. However, to design a lower frequency broadband power amplifier using this architecture will consume large chip area, since multistage matching networks are needed to achieve the bandwidth requirement. Balance amplifiers can achieve broadband gain and good VSWR at the expense of doubling the dc power and chip area [3]. Distributed amplifier (DA) is a well known broadband amplifier configuration, with the advantages of uniform gain, good noise figure and low VSWR performance over a wide frequency range [4]-[7]. One of the major drawbacks of this architecture is the dc power consumption due to the terminating resistors, which the dc current will flow through. There are some more improved architectures to design broad-band power amplifier [8][10]. In [8], one conventional distributed amplifier as the input stage and cascaded two single ended amplifiers as the second stage and output stage was reported. It can provide broadband gain response with $\pm 5 \mathrm{~dB}$ ripple, but the output power is only $16 \mathrm{dBm}$ in average. Conventional distributed amplifier as the input stage cascaded with a CSSDA as the output stage has also been demonstrated [9]. The CSSDA output stage requires a termination resistor in its dc path, thus increasing the power consumption of the circuit significantly. Another amplifier cascading two CDA stages, have also been reported [10], but the dc power consumption is relatively large due to the output DA circuit architecture.

In this paper, a broadband medium power amplifier using $0.15-\mu \mathrm{m}$ GaAs based pHEMT MMIC technology is presented. Two cascaded DA stages are used to provide wideband gain, with a final single-ended power stage to provide higher output power due toe the power matching network. Only two devices are used in each distributed amplifier stage in order to reduce the $\mathrm{dc}$ power consumption. This medium power amplifier demonstrates a measured gain of $21 \pm 1.5 \mathrm{~dB}$ from 15 to $50 \mathrm{GHz}$, output $1-\mathrm{dB}$ compression power $\left(O P_{1 \mathrm{~dB}}\right)$ of 15.1 to $19.1 \mathrm{dBm}$ from 20 to $47 \mathrm{GHz}$, and saturated output power (Psat) of $18-22 \mathrm{dBm}$ from 18 to $50 \mathrm{GHz}$ with a compact chip size of $1.5 \times 1 \mathrm{~mm}^{2}$. The amplifier can cover the frequency from 15 to $50 \mathrm{GHz}$. Thus, it can be used in local multipoint distribution service (LMDS) at $28 \mathrm{GHz}$, and point-to-point microwave radio as well as automotive 24 $\mathrm{GHz}$, instrumentation, and VSAT satellite ground stations. Broadband operation results in flexibility, economics of scale and improved inventory costs [11].

\section{Circuit Design}

Figure 1 shows the circuit schematic diagram of the broadband medium power amplifier. The circuit cascades two distributed amplifier stages and a single transistor power stage. The first and second stages using distributed structure are designed for wide bandwidth and high gain. The third stage is designed for output power. By using this architecture, high gain and flat output power can be achieved over a wide bandwidth. The first stage and 


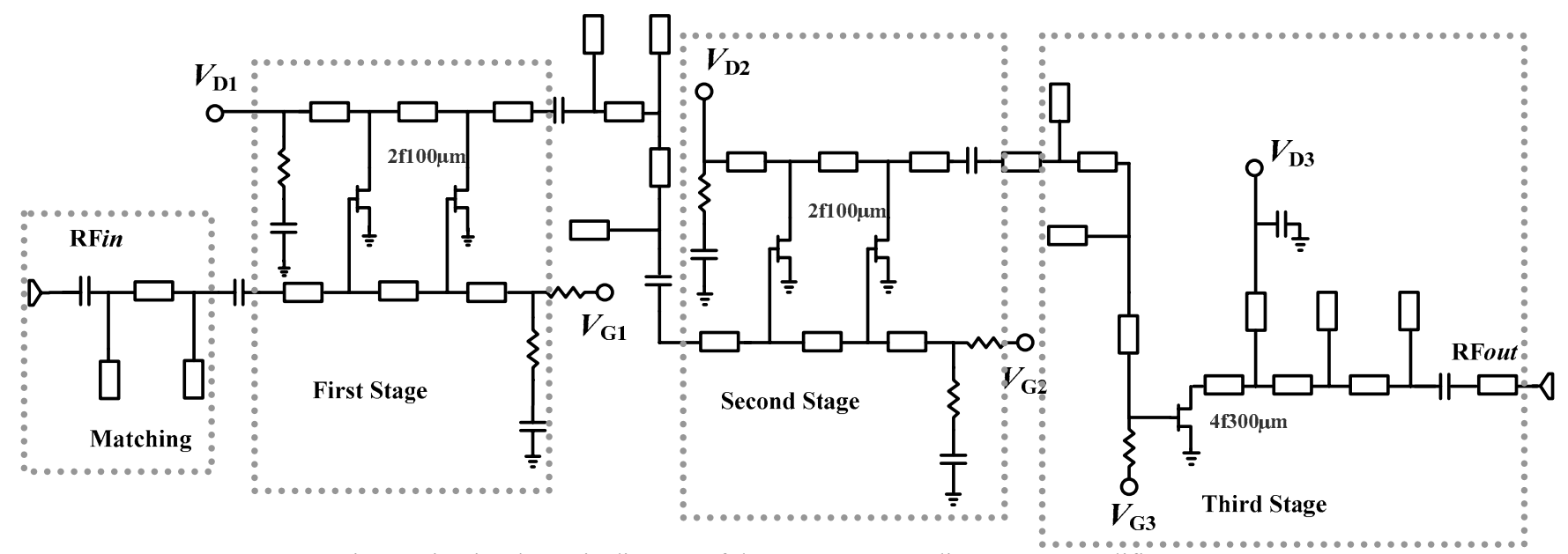

Fig. 1. Circuit schematic diagram of the $15-50 \mathrm{GHz}$ medium power amplifier

the second stage utilize two distributed cells to provide broadband gain. The devices in these two cells are all 2finger with total gate width of $100-\mu \mathrm{m}$ HEMT devices. Since the power dissipation is an important issue for distributed amplifier, there are only two transistors in each stage. Series R-C bypass circuits are used as terminations in the gate and drain bias, and therefore the current will not flow through the resistors and consume dc power on the termination resistors. The third stage is a single transistor amplifier designed for large output power and wide bandwidth. The device size of the third stage is 4finger with total gate width of $300-\mu \mathrm{m}$.

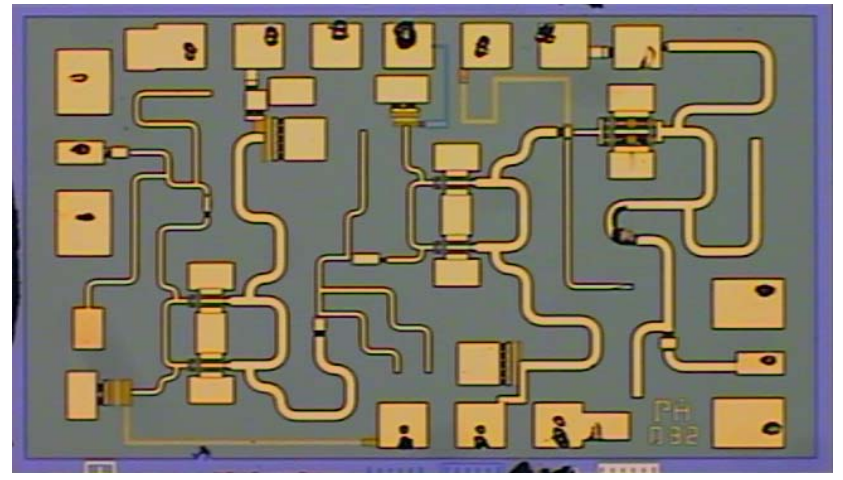

Fig. 2. Chip photo of the $15-50 \mathrm{GHz}$ amplifier with chip size of

$$
1.5 \times 1 \mathrm{~mm}^{2}
$$

This circuit is fabricated using the $0.15-\mu \mathrm{m}$ GaAs pHEMT process provided by WIN Semiconductors. The unit current gain frequency $\left(f_{\mathrm{T}}\right)$ of the device is about 85 $\mathrm{GHz}$, and the maximum oscillation frequency $\left(f_{\max }\right)$ is over $120 \mathrm{GHz}$. The typical breakdown voltage is $10 \mathrm{~V}$ and the peak of trans-conductance is $495 \mathrm{mS} / \mathrm{mm}$. Other passive components such as thin-film resistors, MIM

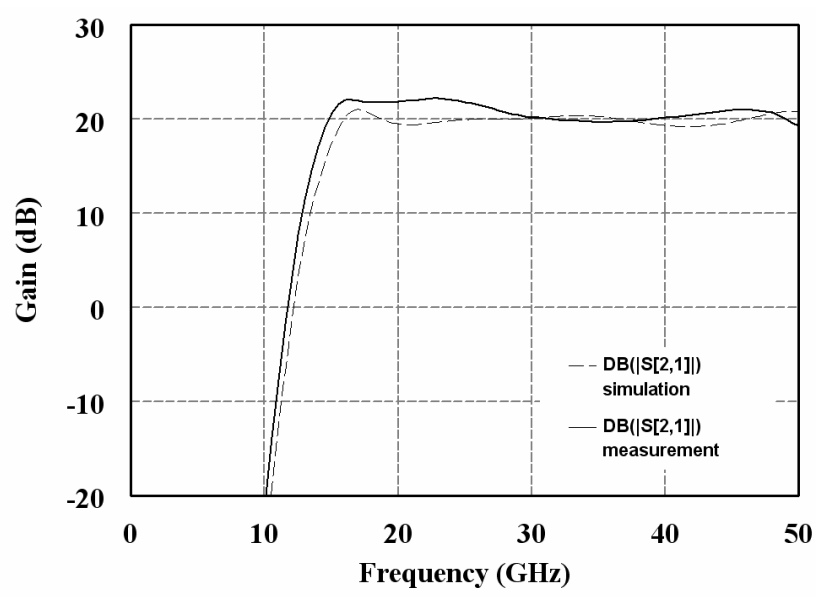

(a)

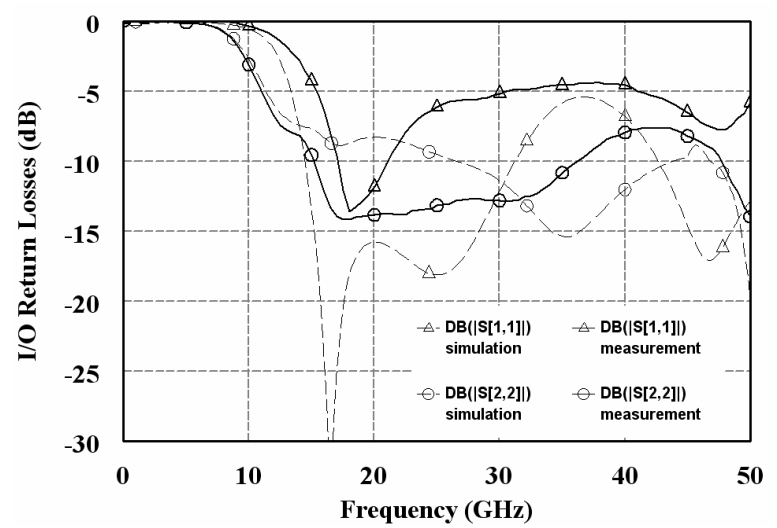

(b)

Fig. 3. Simulated and measured (a) small signal gain, and (b) input and output return loss, versus frequency for 15-50 PA. 
Table I RePorted PERformance of GAAs PHEMT BroAdBAND POWER AMPLIFIERS

\begin{tabular}{|c|c|c|c|c|c|c|c|}
\hline & $\begin{array}{l}\text { Frequency } \\
(\mathrm{GHz})\end{array}$ & Architecture & Process & $P_{\text {SAT }}(\mathrm{dBm})$ & $\begin{array}{l}\text { Gain } \\
(\mathrm{dB})\end{array}$ & $\begin{array}{l}\text { Size } \\
\left(\mathrm{mm}^{2}\right)\end{array}$ & $P_{\mathrm{DC}}(\mathrm{mW})$ \\
\hline [6] & DC-54 & $\begin{array}{c}\text { CDA } \\
\text { (device cascode) }\end{array}$ & $\begin{array}{c}0.15 \mu \mathrm{m} \text { GaAs } \\
\text { HEMT }\end{array}$ & 23 & $15 \pm 0.5$ & 6.07 & 1100 \\
\hline [8] & $18-71$ & $\begin{array}{l}\text { CDA+2 single } \\
\text { stage amplifier }\end{array}$ & $\begin{array}{c}0.15 \mu \mathrm{m} \text { GaAs } \\
\text { pHEMT }\end{array}$ & $16(19 \sim 57 \mathrm{GHz})$ & $20 \pm 5$ & 2.5 & 306 \\
\hline [9] & $0.1-40$ & CDA+2CSSDA & $\begin{array}{c}0.15 \mu \mathrm{m} \text { GaAs } \\
\text { pHEMT }\end{array}$ & 15 & $22 \pm 2$ & 3 & 480 \\
\hline [10] & $4-37$ & 2 CDA & $\begin{array}{c}0.15 \mu \mathrm{m} \text { GaAs } \\
\text { pHEMT }\end{array}$ & $20.6-23.3$ & $15.3 \pm 1$ & 3 & 1642 \\
\hline [11] & $1-40$ & $\begin{array}{l}\text { CDA (device } \\
\text { cascode) }\end{array}$ & $\begin{array}{c}0.15 \mu \mathrm{m} \text { GaAs } \\
\text { pHEMT }\end{array}$ & $20-25$ & $\begin{array}{c}13.5 \pm \\
1.5 \\
\end{array}$ & 2.47 & 1400 \\
\hline [14] & $0.1-65$ & $\begin{array}{l}\text { CDA (device } \\
\text { cascode) }\end{array}$ & $\begin{array}{l}0.15 \mu \mathrm{m} \text { GaAs } \\
\text { MHEMT }\end{array}$ & N/A & $14 \pm 2.5$ & 1.59 & 105 \\
\hline [15] & $18-40$ & $\begin{array}{c}\text { CDA + single } \\
\text { stage amplifier }\end{array}$ & $\begin{array}{c}\text { GaAs } \\
\text { HEMT }\end{array}$ & 14 & 12.5 & 1.53 & 240 \\
\hline [16] & $17-40$ & $\begin{array}{c}\mathrm{DA}+3 \text { single stage } \\
\text { amplifier }\end{array}$ & GaAs HEMT & 21 & 21 & 1.51 & 1170 \\
\hline This work & $15-50$ & $\begin{array}{l}2 \text { CDA + single } \\
\text { stage amplifier }\end{array}$ & $\begin{array}{c}0.15 \mu \mathrm{m} \text { GaAs } \\
\text { pHEMT }\end{array}$ & $\begin{array}{c}18-22(18- \\
50 \mathrm{GHz})\end{array}$ & $21 \pm 1.5$ & 1.5 & 649 \\
\hline
\end{tabular}

capacitors, spiral inductors, and air-bridges are available. The 6" wafer is thinned down to 4-mil for the gold plating of the backside, and slot via holes are used for dc grounding.

The complete circuit is simulated using ADS circuit simulator [12]. All the passive components, such as junctions, capacitances, and transmission lines are simulated using a full-wave EM simulator provided by Microwave Office [13]. The chip photo is shown in Fig. 2, with a chip size of $1.5 \mathrm{~mm} \times 1 \mathrm{~mm}$.

\section{MEASUREMENT}

The performance of the chip was measured via onwafer probing. An HP8510C measurement system is used to measure the small signal frequency response to from 45 $\mathrm{MHz}$ to $50 \mathrm{GHz}$.

Figure 3(a) shows the measured and simulated small signal gain, while Fig. 3(b) presents the input and output return losses of this power amplifier from 0.045 to 50 $\mathrm{GHz}$. The first stage is biased at $\mathrm{Vgs}=-0.25 \mathrm{~V}, \mathrm{Vds}=3$ $\mathrm{V}$ with $\mathrm{Id}=47 \mathrm{~mA}$, while the second stage is biased at $\mathrm{Vgs}=-0.25 \mathrm{~V}, \mathrm{Vds}=4 \mathrm{~V}$ and Id with $58 \mathrm{~mA}$, and the third stage at $\mathrm{Vgs}=-0.25 \mathrm{~V}, \mathrm{Vds}=3 \mathrm{~V}$ with $\mathrm{Id}=69 \mathrm{~mA}$. The small signal gain is $21 \mathrm{~dB}$ with less than $1.5 \mathrm{~dB}$ ripple over 15 to $50 \mathrm{GHz}$. The total dc power consumption is $649 \mathrm{~mW}$. Because the third stage of this amplifier is a band pass design, it has no gain at lower frequency (below
$15 \mathrm{GHz}$ ). Power performance was measured using an HP83650B signal generator and a power amplifier for large RF power input up to $50 \mathrm{GHz}$. Figure 4 illustrates the measurement and simulation of saturated power vs. the frequency and the measured and simulated output $P_{1 \mathrm{~dB}}$ $\left(O P_{1 \mathrm{~dB}}\right)$ versus frequency. The measured $O P_{1 \mathrm{~dB}}$ is between 15.1 to $19.1 \mathrm{dBm}$ from 20 to $47 \mathrm{GHz}$. The measured saturated power is between 18 to $22 \mathrm{dBm}$ from 18 to $50 \mathrm{GHz}$. Table I compares the recently reported broad-band amplifiers, including reported literature and commercial products. Compared with the reported broadband power amplifiers, this chip provides flat gain, $20 \mathrm{dBm}$ average power over a wide-bandwidth in a compact small chip size.

\section{CONCLUSION}

A $15-50 \mathrm{GHz}$ high gain GaAs MMIC medium power amplifier has been designed, fabricated, and measured. It provides flat gain and sufficient power over the operating frequency. The small signal gain is $21 \mathrm{~dB}$ with $1.5 \mathrm{~dB}$ ripple over 15 to $50 \mathrm{GHz}$. The saturated power is 18 to 22 $\mathrm{dBm}$ output power over 18 to $50 \mathrm{GHz}$ and the $O P_{1 \mathrm{~dB}}$ is 15.1 to $19.1 \mathrm{dBm}$ from 20 to $47 \mathrm{GHz}$. The wide bandwidth and power make this amplifier suitable in many microwave system applications, such as measurement instruments, and transceiver gain block. 


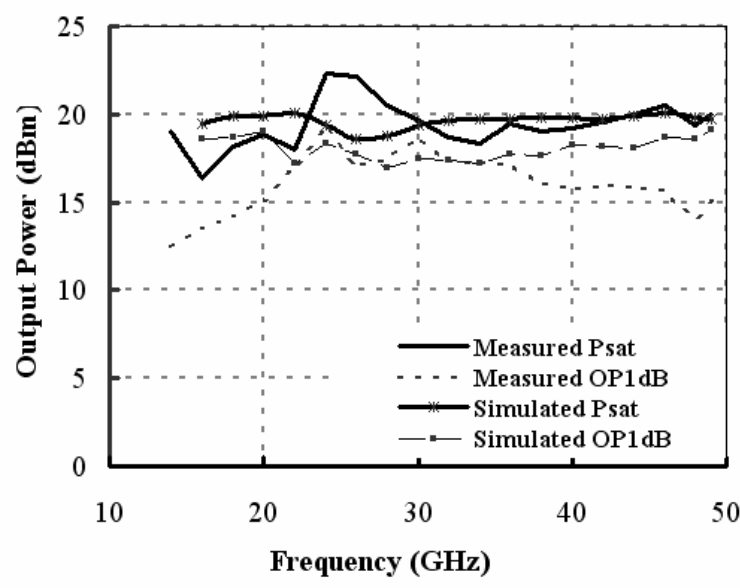

Fig. 4. Simulated and measured $O P_{1 \mathrm{~dB}}$ and $P_{\mathrm{SAT}}$ vs. frequency for the $15-50 \mathrm{GHz}$ medium power amplifier.

\section{ACKNOWLEDGEMENT}

This work is supported in part by the National Council of Taiwan, R.O.C. under Projects NSC 93-2219-E-002024, NSC 93-2213-E-002-033 and NSC 93-2752-E-002002-PAE. The chip is fabricated on WIN semiconductor. The authors wish to acknowledge the software support of Chip Implementation Center of Taiwan.

\section{REFERENCES}

[1] L. Samoska, Y. C. Leong, "65-145 GHz InP MMIC HEMT medium power amplifier," 2001 IEEE MTT-S Int. Microwave Symp. Dig., pp.1805-1808, May 2001.

[2] Y. C. Leong, S. Weinreb, "Full W-band MMIC medium power amplifier," 2000 IEEE MTT-S Int. Microwave Symp Dig., vol 2, pp. 951-954, June 2000. [3] Vaz, J.C., and Freire, J.C.," Millimeter-wave monolithic power amplifier for mobile broad-band systems" IEEE Trans. Microwave Theory Tech., vol. 49, 2001, June, pp.1211-12152196
[4] H.B Demuth, "An investigation of the iterative synthesis of distributed amplifiers," Stanford Univ. Elect. Lab., Technique Report no. 77; August 1954

[5] Y. Baeyens et al., "InP D-HBT ICs for $40-\mathrm{Gb} / \mathrm{s}$ and higher bit rate lightwave transceivers." IEEE J. Solid State Circuits, vol. 37, pp. 1152-1159, Sept. 2002

[6] H.Shigematsu, N.Yoshida, M.Sato, T.Hirose, and Y. Watanabe, "45-GHz distributed amplifier with linear $6 \mathrm{Vp}$ p output for a $40-\mathrm{Gb} / \mathrm{s} \mathrm{LiNbO} 3$ modulator driver circuit," 2001 MTT-S Int Microwave Symp. Dig., vol. 1, pp.137-140, June 2001.

[7] C. Meliani, G. Post, G. Rondeau, J. Decobert, W. Mouzannar, E. Dutisseuil and R. Lefevrem "DC-92 GHz ultra-broadband gain InP HEMT amplifier with $410 \mathrm{GHz}$ gain-bandwidth product," Electronic Lett., vol.38, pp.11751176, Sept. 2002

[8] P. S. Wu, T. W. Huang, and H. Wang, "An 18-71 GHz multi-band and high gain GaAs MMIC medium power amplifier for millimeter-wave applications," IEEE MTT-S Int. Microwave Symp. Dig., June 2003, pp. 863-866

[9] K. L. Deng, T.W. Huang, and H.Wang, "Design and analysis of novel high-gain and broad-band GaAs pHEMT MMIC distributed amplifiers with traveling-wave gain stages," IEEE Trans. Microwave Theory Tech., vol. 51, 2003, pp.2188-2196

[10] M.-C. Chuang, M.-F. Lei,and H. Wang, “ A Broadband Medium Power Amplifier for Millimeter Applications" in Asia Pacific Microwave Conf., 2005,pp.

[11] Kohei Fujii, and Henrik Morkner "Two novel broadband MMIC amplifiers in SMT package for 1 to $40 \mathrm{GHz}$ low cost applications," $35^{\text {th }}$ European Microwave Conference 2003. pp.1083-1086

[12] Advanced Design System 2003C, Agilent

[13] Microwave Office, AWR

[14] M. S Henis, C. F. Campbell, M.-Y. Kao, M.E. Muir, and J. M. Carrol, "A GaAs MHEMT distributed amplifier with $300 \mathrm{GHz}$ gain-bandwidth product for $40-\mathrm{Gb} / \mathrm{s}$ optical application," 2002 IEEE MTT-S Int. Microwave Symp. Dig., pp.1061-1064, June 2002.

[15] LMA406 Data Sheet, Filtronic, Santa clara, CA, 2002

[16] HMC283 Data, Hittite Microwave Corporation, Chelmsford, MA, 2002 